\title{
Preoperative Gemcitabine and Oxaliplatin in a Patient with Ovarian Metastasis from Pancreatic Cystadenocarcinoma
}

\author{
Mariacristina Di Marco ${ }^{a}$ Silvia Vecchiarelli ${ }^{\mathrm{a}}$ \\ Marina Macchini ${ }^{\mathrm{a}}$ Raffaele Pezzilli ${ }^{\mathrm{b}}$ Donatella Santini ${ }^{\mathrm{C}}$ \\ Riccardo Casadei $^{\text {d }}$ Lucia Calculli $^{\mathrm{e}}$ Sokol Sina $^{a}$ \\ Riccardo Panzacchi ${ }^{\mathrm{c}}$ Claudio Ricci ${ }^{\mathrm{d}} \quad$ Elisa Grassi ${ }^{\mathrm{a}}$ \\ Francesco Minni $^{d}$ Guido Biasco ${ }^{a}$ \\ Departments of 'Hematology and Oncological Sciences 'L. \& A. Seràgnoli', \\ ${ }^{b}$ Digestive Diseases and Internal Medicine, ${ }^{c}$ Pathology, ${ }^{d}$ Surgery and ${ }^{\mathrm{e}}$ Radiology, \\ University of Bologna, S. Orsola-Malpighi Hospital, Bologna, Italy
}

\section{Key Words}

Pancreatic cancer - Mucinous pancreatic cystadenocarcinoma - Metastatic cystadenocarcinoma $\cdot$ Gemcitabine and oxaliplatin (GEMOX) - Chemotherapy

\begin{abstract}
We describe a case of clinical benefit and partial response with gemcitabine and oxaliplatin (GEMOX) in a young patient with ovarian metastasis from cystadenocarcinoma of the pancreas. A young woman complained of abdominal pain and constipation. Computed tomography (CT) and magnetic resonance imaging scans disclosed two bilateral ovarian masses with pancreatic extension. She underwent bilateral ovarian and womb resection. During surgery peritoneal carcinosis, a pancreatic mass and multiple abdominal lesions were found. The final diagnosis was mucinous pancreatic cystadenocarcinoma with ovarian and peritoneal metastases. She started chemotherapy with GEMOX (gemcitabine $1,000 \mathrm{mg} / \mathrm{m}^{2} / \mathrm{d} 1$ and oxaliplatin $100 \mathrm{mg} / \mathrm{m}^{2} / \mathrm{d} 2$ every 2 weeks). After 12 cycles of chemotherapy a CT scan showed reduction of the pancreatic mass. She underwent distal pancreatic resection, regional lymphadenectomy and splenectomy. Pathologic examination documented prominent fibrous tissue and few neoplastic cells with mucin-filled cytoplasm. Chemotherapy was continued with gemcitabine as adjuvant treatment for another 3 cycles. There is currently no evidence of disease. As reported in the literature, GEMOX is associated with an improvement in progression-free survival and clinical benefit in patients with advanced pancreatic cancer. This is an interesting case in whom GEMOX transformed inoperable pancreatic cancer into a resectable tumor.
\end{abstract}




\section{Introduction}

Mucin-producing cystic lesions of the pancreas currently constitute a well-recognized entity. Since they were first identified by Becourt in 1830, the major unsolved issue has been to have a definitive preoperative diagnosis, because different cystic neoplasms require different treatments [1]. In 1996, the World Health Organization distinguished two types of mucinous cystic tumors: intraductal papillary mucinous neoplasms and mucinous cystic neoplasms (MCNs) [2]. MCNs range from benign mucinous cystadenoma to malignant cystadenocarcinoma and have a potential for malignant degeneration, as originally reported by Compagno and Oertel in 1978 [3]. MCNs are defined as large, thick-walled, septated cysts with no communication with the ductal system and characterized by the presence of ovarian-type stroma. This stroma is not only morphologically similar to that of the ovarian cortex, but also expresses estrogen and progesterone receptors detectable by immunohistochemistry. This distinctive mesenchyma helps distinguish MCNs from other similar tumors (i.e. intraductal papillary mucinous neoplasms) [4].

The prognosis of resectable MCN is excellent whereas the prognosis of mucinous cystadenocarcinoma is poor. Complete surgical excision of benign MCNs is curative $[3,5,6]$, whereas the long-term survival of patients with mucinous cystadenocarcinoma is controversial. Although the efficacy of neoadjuvant or postoperative adjuvant chemotherapy or radiation therapy for mucinous cystadenocarcinomas of the pancreas is unknown, two reports suggest a possible benefit of chemoradiation therapy $[7,8]$.

The present report describes a case of clinical benefit and partial response with gemcitabine and oxaliplatin (GEMOX) in a patient with pancreatic mucinous cystadenocarcinoma with ovarian metastasis, from inoperable disease into a radically resected neoplasm. We also review the literature and discuss the current principles of management.

\section{Case Report}

A 41-year-old woman presented with several months' history of dyspepsia, postprandial fullness, nausea, constipation, abdominal distension and epigastric pain, treated for a long time with proton pump inhibitors without benefit. Both her medical and family history were unremarkable. Because of the rapid aggravation of symptoms within a few months, the patient underwent an abdominal computed tomography (CT) scan that disclosed a hypodense area in the body and tail of the pancreas and a pelvic cystic mass of $129 \times 80 \mathrm{~mm}$. The pancreatic lesion (measuring $4 \mathrm{~cm}$ ), confirmed by abdominal magnetic resonance imaging, was hypointense on T1-weighted scans and a large macrocystic mass of $14.5 \mathrm{~cm}$ with septations was seen in the pelvis involving the left ovary, with another mass of $7.1 \times 5.3 \mathrm{~cm}$ involving the right ovary.

In November 2008 the patient underwent surgical removal of the bulky ovarian mass. Intraoperatively, peritoneal metastases were found with parietal lumps infiltrating the vagina, rectum and transverse colon. The voluminous pancreatic mass showed splenoportal venous confluence infiltration, with diffusion to the posterior gastric wall and lesser omentum. The surgical specimen included womb and ovaries infiltrated by two macrocystic lesions, producing mucoid material, of $6.5 \times 6 \times 4 \mathrm{~cm}$ and $10 \times 9 \times 5 \mathrm{~cm}$, respectively. The final diagnosis was mucinous cystadenocarcinoma infiltrating the ovaries with a necrotic component and an extensive involvement of the capsule with peritoneal invasion ( $\underline{\text { fig. } 1}$ ). She was discharged on the ninth postoperative day.

In December 2008 the patient started chemotherapy with GEMOX (gemcitabine 1,000 mg/m²/d and oxaliplatin $100 \mathrm{mg} / \mathrm{m}^{2} / \mathrm{d} 2$ every 2 weeks). Here clinical condition was compromised and 
ECOG performance status was 2. The serum CA19-9 level was $654.20 \mathrm{IU} / \mathrm{ml}$ (reference range $0.00-37.00 \mathrm{IU} / \mathrm{ml}$ ) and the serum CA125 level was 98 . IU $/ \mathrm{ml}$ (reference range $0.00-35.00 \mathrm{IU} / \mathrm{ml}$ ). After 6 cycles of chemotherapy a CT scan showed stable disease: a heterogeneously hypodense lesion at the pancreatic body $(3 \mathrm{~cm})$ and complete thrombosis of the splenic vein (G4) with opening of the perigastrosplenic collateral circulation. The tumor extended posteriorly, encompassing the origin of the celiac axis with artery thrombosis at splenic origin (G4) and was in close continuity with a missing adipose cleavage plane, with the lateral margin of the superior mesenteric artery at its origin (G1) (fig. 2). The serum CA19-9 level was $26.00 \mathrm{IU} / \mathrm{ml}$ (reference range $0.00-37.00 \mathrm{IU} / \mathrm{ml}$ ) and the serum CA125 level was $16.90 \mathrm{IU} / \mathrm{ml}$ (reference range $0.00-35.00 \mathrm{IU} / \mathrm{ml}$ ). Since the patient's clinical condition was good (ECOG performance status 0 ) with a reduction of abdominal pain and weight gain of $7 \mathrm{~kg}$ and since the therapy was tolerated well, she continued the medical treatment with another 6 cycles of chemotherapy.

In August 2009 a repeat CT scan showed further reduction of the pancreatic mass (fig. 3 ), measuring $2.4 \times 1.2 \mathrm{~cm}$, and serum CA19-9 and CA125 levels continued to be normal. The patient also underwent a CT/PET scan that showed no pathologic uptake of ${ }^{18} \mathrm{~F}$-FDG. Surgical resection was then possible, so our patient underwent exploratory laparotomy with distal pancreatectomy, regional lymphadenectomy and splenectomy. During surgery there was no evidence of peritoneal carcinosis or ascites. The pancreatic specimen measured $6 \times 3 \times 1 \mathrm{~cm}$ and appeared to have an increased consistency. Histopathologic examination of surgical specimens revealed microscopic foci $(<2 \mathrm{~mm})$ of well-differentiated pancreatic ductal adenocarcinoma and extensive chemotherapy-induced fibrosis. Omental tissue was undamaged and there was no evidence of lymph node involvement. After surgery we decided to continue chemotherapy with gemcitabine as an adjuvant treatment for another 3 cycles. CT scan showed no disease, the patient's clinical condition was excellent, she stopped the treatment and underwent intensive follow-up. At present, 24 months after surgical resection, there is no evidence of disease relapse.

\section{Discussion}

The incidence of mucinous cystadenocarcinomas is $1 \%$ of pancreatic neoplasms. MCNs present most frequently in young women and in the body/tail of the pancreas (94.6\%). Mean age at diagnosis is 47 years (range 18-95), whereas median age at diagnosis is higher for malignant MCNs with a difference of approximately 15 years [9]. The median diameter of the lesions is $8.7 \mathrm{~cm}$, but they can be very large (range $0.6-35 \mathrm{~cm}$ ), and many studies suggest that size is a reliable predictor of the tumor's malignant potential [10].

MCNs do not communicate with the pancreatic ductal system and, microscopically, the cysts are lined by tall columnar, mucin-containing cells [11]. The presence of ovarian-like stroma is a necessary element to confirm the diagnosis of MCN $[5,12]$. Several theories have been proposed to explain the pathogenesis of ovarian-type stroma common to all MCNs. Theories include a common origin in epithelial cells that cover the embryonic gonads in early fetal life and the possibility that neoplastic epithelial cells of MCNs induce ovarian stromal differentiation [13]. Alpha-inhibin immunoreactivity has been found in the ovarian-like stroma of MCNs, suggesting that they may be embryologically derived from mullerian elements $[14,15]$. However, the exact pathogenesis of MCNs remains unsettled.

During the past decade, several investigations have concluded that many cases previously diagnosed as primary mucinous carcinoma were actually metastatic to the ovary $[16,17]$. Mucinous tumors may arise from a variety of sites, particularly within the gastrointestinal tract (including the colon, appendix and pancreas) and less often the stomach and biliary tract. 
Although difficulties in distinguishing between primary and metastatic ovarian tumors are well recognized, since many years $[18,19]$ it is evident that a substantial proportion of tumors previously considered to be ovarian primaries actually represent secondary ovarian involvement by tumors elsewhere in the body and that it is important for the multidisciplinary team to have a low threshold of suspicion and that abdominal exploration at the time of surgery (appendicectomy) and radiological review are undertaken before a mucinous ovarian tumor is considered as primary.

Considering these data, the possibility of metastasis should always be considered in cases with a known extraovarian primary tumor. In our case the index of suspicion for secondary ovarian involvement was very high considering the pancreatic lesion and the following data: bilateral ovarian involvement, the metastatic tumor histologically similar to the primary but appearing little more mature, focal patterns almost exclusively seen in metastases, such as signet ring cells or abundant extracellular pools of mucin.

Fewer than $20 \%$ of patients with mucin-producing lesions present an invasive carcinoma (mucinous cystadenocarcinoma) with a 5-year disease-specific survival of $57 \%$. The prognosis of a benign MCN is excellent, whereas the prognosis of mucinous cystadenocarcinoma is poor: its recurrence rate and the incidence of metastasis is unpredictable and reported within a wide range [5, 6, 20]. Sarr et al. [6] reported that, after pancreatic resection, patients with mucinous cystadenocarcinoma had a dismal prognosis.

Complete surgical excision of benign MCNs is curative $[3,5,6]$, whereas the long-term survival of patients with mucinous cystadenocarcinoma remains controversial. It is largely accepted that the prognosis of unresectable mucinous adenocarcinoma is substantially better than that of the usual noncystic ductal adenocarcinoma of the pancreas [3]. However there is no consensus on this [5, 21], and widely varied and unpredictable recurrence rates and incidence of metastases have been noted [6]. Sarr et al. [6] reported a 5-year survival rate of patients with resected mucinous cystadenocarcinoma ranging from 50 to $70 \%$, significantly better than that of ordinary ductal adenocarcinomas. However, in case of unresectable cystadenocarcinoma the prognosis is as poor as that for unresectable pancreatic adenocarcinoma $[6,22]$.

Few reports have investigated the use of chemotherapy, and occasionally radiotherapy, in the adjuvant setting, so the efficacy of neoadjuvant or postoperative adjuvant chemotherapy or radiation therapy for mucinous cystadenocarcinomas of the pancreas is unknown. Two reports suggest the possible benefit of chemoradiation therapy [7, 8]. Sarr et al. [6] suggested a role for adjuvant treatment if tissue invasion is present, even in the absence of lymph node metastasis. More studies are needed to prove the efficacy of chemoradiation, whether in the adjuvant or neoadjuvant setting $[7,8]$.

In conclusion, our case report documents the clinical benefit of and partial response to GEMOX in a patient with pancreatic mucinous cystadenocarcinoma with ovarian metastasis. This is the first report of metastatic mucinous cystadenocarcinoma of the pancreas responding to platinum-derived chemotherapy, transforming inoperable disease into a completely resectable pancreatic cancer. 


\begin{tabular}{r|l|l|l}
$\begin{array}{r}\text { Case Reports in } \\
\text { Gastroenterology }\end{array}$ & $\begin{array}{l}\text { Case Rep Gastroenterol 2012;6:530-537 } \\
\text { DOI: 10.1159/000341513 }\end{array}$ & $\begin{array}{l}\text { Published online: } \\
\text { August 1, 2012 }\end{array}$ & $\begin{array}{l}\text { @ 2012 S. Karger AG, Basel } \\
\text { ISSN 1662-0631 } \\
\text { www.karger.com/crg }\end{array}$ \\
\hline
\end{tabular}

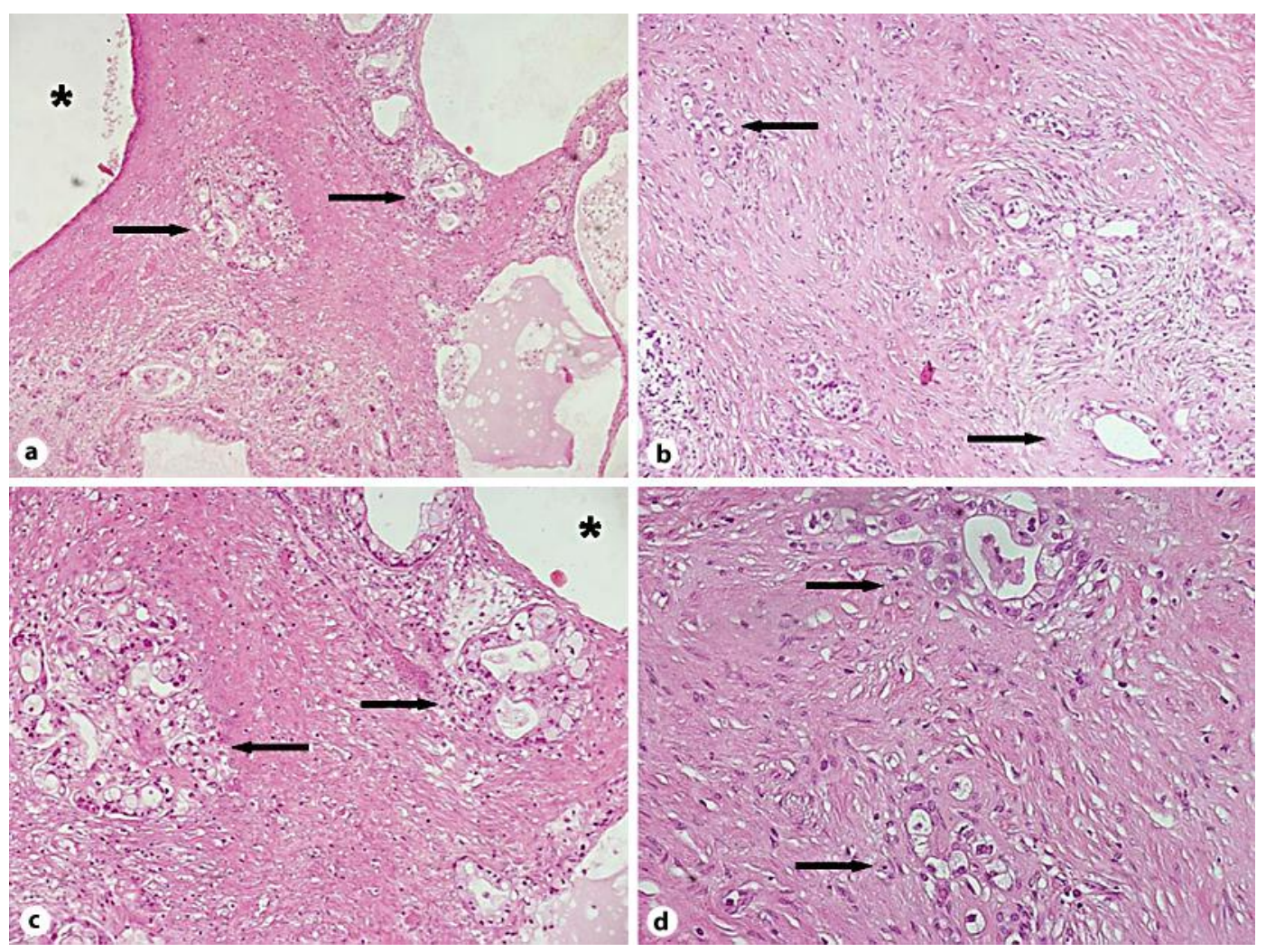

Fig. 1. Left column: a Low-power appearance of the ovarian lesion, displaying cystic spaces (asterisks) alongside with glandular areas (arrows). Both are lined by mucin-filled cells $(\mathrm{H} \& \mathrm{E}, \times 10)$. c Higher-power view of the glands depicted above showing infiltrating pattern and malignant cytology (H\&E, $\times 20)$. Right column: b Post-chemotherapeutic appearance of the pancreatic lesion. On a background of prominent fibrous tissue, few neoplastic cells (arrows) are noticeable (H\&E, $\times 20$ ). d At higher magnification, the neoplastic cells show mucin-filled cytoplasm (H\&E, $\times 40)$. 


\begin{tabular}{r|l|l|l}
$\begin{array}{r}\text { Case Reports in } \\
\text { Gastroenterology }\end{array}$ & $\begin{array}{l}\text { Case Rep Gastroenterol 2012;6:530-537 } \\
\text { DOI: 10.1159/000341513 }\end{array}$ & $\begin{array}{l}\text { Published online: } \\
\text { August 1, 2012 }\end{array}$ & $\begin{array}{l}\text { @ 2012 S. Karger AG, Basel } \\
\text { ISSN 1662-0631 } \\
\text { www.karger.com/crg }\end{array}$ \\
\hline
\end{tabular}
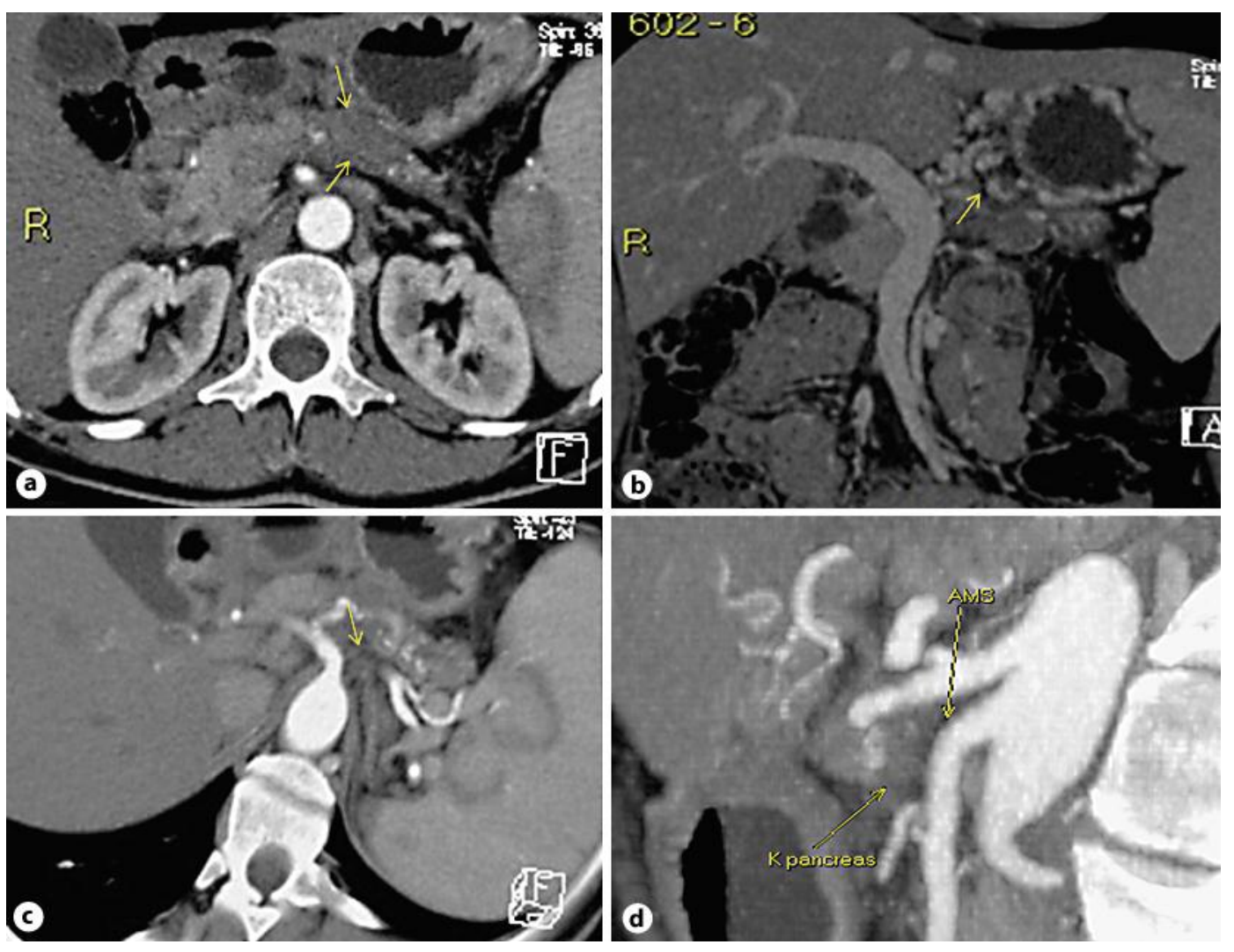

Fig. 2. CT scan after 6 cycles of chemotherapy showed stable disease. a Heterogeneously hypodense neoformation at the pancreatic body. b Complete thrombosis of the splenic vein (G4) with opening of perigastrosplenic collateral circulation. $\mathbf{c}$ The tumor extended posteriorly encompassing the origin of the celiac axis with artery thrombosis at splenic origin (G4). $\mathbf{d}$ Close relationship of continuity, with a missing adipose cleavage plane, with lateral margin of the superior mesenteric artery at origin (G1). 

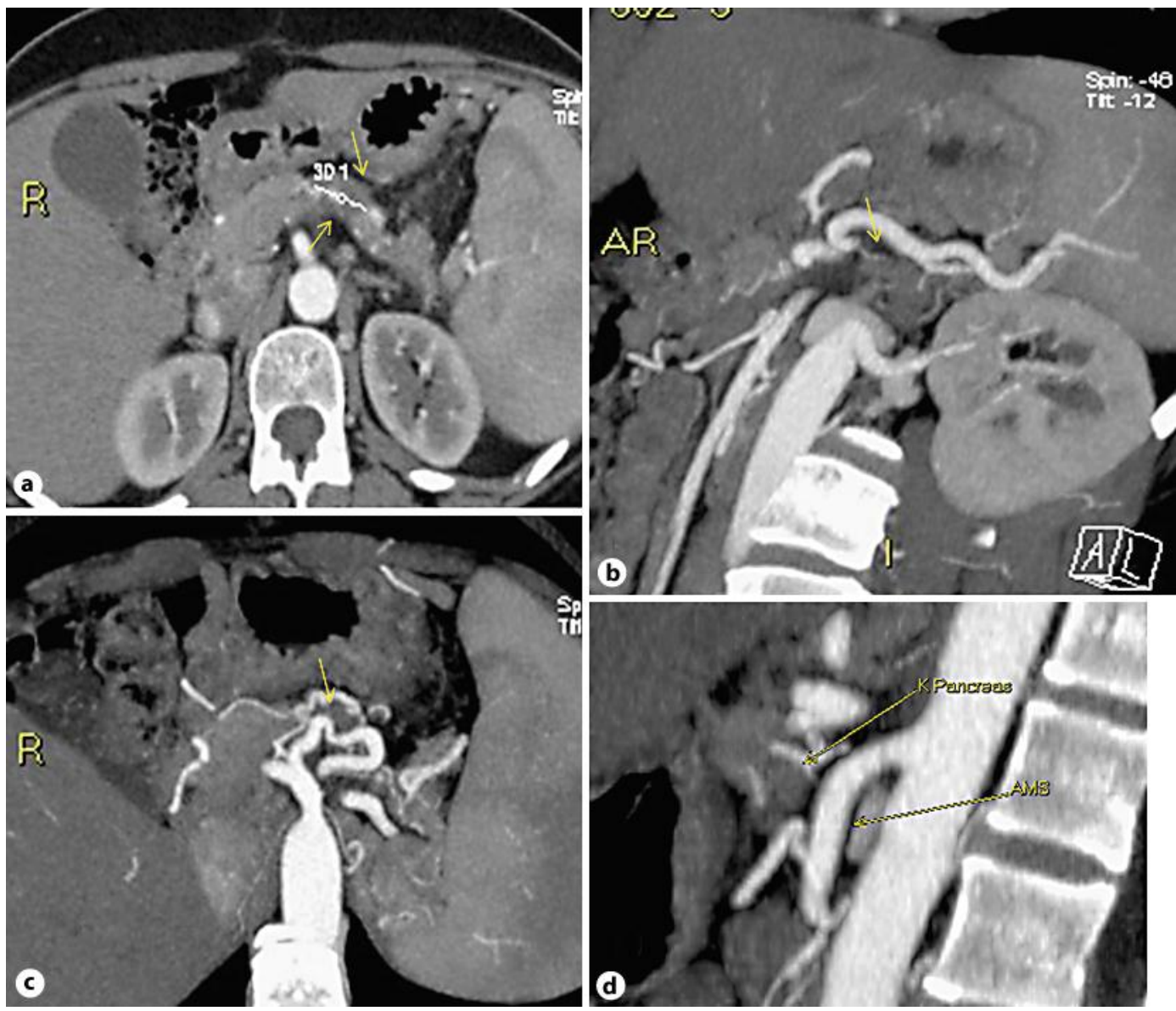

Fig. 3. In August 2009 a repeat CT scan showed further reduction of the pancreatic lesion (a) with partial revascularization of splenic artery origin $(b, c)$ and the appearance of a cleavage plane with the left margin of the superior mesenteric artery (d).

\section{References}

1 Salvia R, Festa L, Butturini G, Capelli P, Pederzoli P: Pancreatic cystic tumors. Minerva Chir 2004;59:185-207.

2 Kloppel G, Solcia E, Longnecker DS, Capella C, Sobin LH: Histological typing of tumors of the exocrine pancreas; in World Health Organization (ed): International Histological Classification of Tumors, ed 2. Berlin, Springer, 1996, pp 15-21.

3 Compagno J, Oertel JE: Mucinous cystic neoplasms of the pancreas with overt and latent malignancy (cystadenocarcinoma and cystadenoma). A clinicopathologic study of 41 cases. Am J Clin Pathol 1978;69:573-580.

4 Jeurnink SM, Vleggaar FP, Siersema PD: Overview of the clinical problem: facts and current issues of mucinous cystic neoplasms of the pancreas. Dig Liver Dis 2008;40:837-846.

5 Warshaw AL, Compton CC, Lewandrowski K, Cardenosa G, Mueller PR: Cystic tumors of the pancreas. New clinical, radiologic, and pathologic observations in 67 patients. Ann Surg 1990;212:432-443.

-6 Sarr MG, Carpenter HA, Prabhakar LP, Orchard TF, Hughes S, van Heerden JA, DiMagno EP: Clinical and pathologic correlation of 84 mucinous cystic neoplasms of the pancreas: can one reliably differentiate benign from malignant (or premalignant) neoplasms? Ann Surg 2000;231:205-212.

7 George DH, Murphy F, Michalski R, Ulmer BG: Serous cystadenocarcinoma of the pancreas: a new entity? Am J Surg Pathol 1989;13:61-66. 
8 Doberstein C, Kirchner R, Gordon L, Silberman AW, Morgenstern L, Shapiro S: Cystic neoplasms of the pancreas. Mt Sinai J Med 1990;57:102-105.

9 Sakorafas GH, Sarr MG: Cystic neoplasm of the pancreas: what a clinician should know. Cancer Treat Rev 2005;31:507-535.

10 Goh BK, Tan YM, Chung YF, Chow PK, Cheow PC, Wong WK, Ooi LL: A review of mucinous cystic neoplasms of the pancreas defined by ovarian-type stroma: clinicopathological features of 344 patients. World J Surg 2006;30:2236-2245.

$\checkmark 11$ Roggin KK, Chennat J, Oto A, Noffsinger A, Briggs A, Matthews JB: Pancreatic cystic neoplasm. Curr Probl Surg 2010;47:459-510.

12 Reddy RP, Smyrk TC, Zapiach M, Levy MJ, Pearson RK, Clain JE, Farnell MB, Sarr MG, Chari ST: Pancreatic mucinous cystic neoplasm defined by ovarian stroma: demographics, clinical features, and prevalence of cancer. Clin Gastroenterol Hepatol 2004;2:1026-1031.

13 Campbell F, Azadeh B: Cystic neoplasm of the exocrine pancreas. Histopathology 2008;52:539-551.

14 Ridder GJ, Mascheck H, Flemming P, Nashan B, Klempnauer J: Ovarian-like stroma in and invasive mucinous cystadenocarcinoma of the pancreas positive for inhibin. A hint concerning its possible histogenesis. Virchows Arch 1998;432:451-454.

15 Zamboni G, Scarpa A, Bogina G, Iacono C, Bassi C, Talamini G, Sessa F, Capella C, Solcia E, Rickaert F, Mariuzzi GM, Klöppel G: Mucinous cystic tumors of the pancreas: clinicopathological features, prognosis, and relationship to other mucinous cystic tumors. Am J Surg Pathol 1999;23:410-422.

16 Hart WR: Diagnostic challenge of secondary (metastatic) ovarian tumors simulating primary endometrioid and mucinous neoplasms. Pathol Int 2005;55:231-243.

17 Seidman JD, Kurman RJ, Ronnett BM: Primary and metastatic mucinous adenocarcinomas in the ovaries: incidence in routine practice with a new approach to improve intraoperative diagnosis. Am J Surg Pathol 2003;27:985-993.

18 Ulbright TM, Roth LM, Stehman FB: Secondary ovarian neoplasia. A clinicopathologic study of 35 cases. Cancer 1984;53:1164-1174.

19 Leen SL, Singh N: Pathology of primary and metastatic mucinous ovarian neoplasms. J Clin Pathol 2012;65:591-595

-20 Wilentz RE, Albores-Saavedra J, Zahurak M, Talamini MA, Yeo CJ, Cameron JL, Hruban RH: Pathologic examination accurately predicts prognosis in mucinous cystic neoplasms of the pancreas. Am J Surg Pathol 1999;23:1320-1327.

21 ReMine SG, Frey D, Rossi RL, et al: Cystic neoplasms of the pancreas. Arch Surg 1987;122:443-446.

-22 Wilentz RE, Albores-Saavedra J, Hruban RH: Mucinous cystic neoplasms of the pancreas. Semin Diagn Pathol 2000;17:31-42. 